\title{
The Value of National Early Warning Score in Predicting the Condition and Prognosis of Elderly Patients in Emergency Department
}

\author{
RONG XIN WANG*, JING WANG AND SHUI QING HU \\ Emergency Department, ${ }^{1}$ Department of Gastroenterology, Xuanwu Hospital, Capital Medical University, No. 45 Changchun \\ Street, Xicheng District, Beijing 100053, China
}

Wang et al.: Value of NEWS in Predicting the Condition and Prognosis of Elderly Patients

\begin{abstract}
To investigate the value of national early warning score for predicting the condition and prognosis of elderly patients in the emergency department. 1034 elderly patients admitted to our hospital from January 2019 to December 2019 were divided into general ward group and intensive care unit group according to the direction of emergency treatment; meanwhile after $1 \mathrm{mo}$, patients were divided into death and survival groups according to their actual conditions. All patients were evaluated using the modified early warning score and the national early warning score and the prognostic value of the national early warning score for elderly patients was assessed using the receiver operating characteristic curve. Comparison of gender, age, systolic blood pressure and body temperature between the general ward group and intensive care unit group, the differences were not statistically significant $(p>0.05)$, the differences in consciousness, respiratory support, mode of admission and renal failure between the two groups were statistically significant $(\mathbf{p}<0.05)$. The pulse rate, respiratory rate, modified early warning score and national early warning score were significantly higher and oxygen saturation was significantly lower in the intensive care unit group than that of in the general ward group $(p<0.05)$. In the death group and the survival group, the differences in sex, age, systolic blood pressure, pain and temperature were not statistically significant $(p>0.05)$; the differences in consciousness, respiratory support, mode of admission and renal failure were statistically significant $(p<0.05)$. The pulse rate, respiratory rate, modified early warning score and national early warning score were significantly higher and oxygen saturation was significantly lower in the death group than that of in the survival group $(p<0.05)$. Frequency, modified early warning score and correction modified early warning score were all higher than those in the surviving group and oxygen saturation was lower than those in the surviving group. The results of receiver operating characteristic curve showed that the index and sensitivity of national early warning score was significantly higher than that of modified early warning score. Both modified early warning score and national early warning score can predict the condition and prognosis of elderly patients in the emergency department. The national early warning score is closer to the actual situation of elderly patients, more accurate and comprehensive than the modified early warning score score in reflecting the criticality and changes in the condition of elderly patients and has a greater ability to predict the prognosis of patientsis.
\end{abstract}

Key words: Modified early warning score, National early warning score, emergency, elderly patients, receiver operating characteristic curve

In the daily emergency work, especially in the first line emergency scene, the treatment conditions are often relatively simple. Due to the lack of effective diagnosis of the patient's condition, medical staff only rely on subjective judgment and clinical experience for diagnosis and treatment, which may cause some patients to miss the best treatment time and treatment method $^{[1]}$ and the severity of the patient's condition is easy to be ignored, which will directly affect the next step of treatment for patients. With the aggravation of aged society in China, the number of elderly patients in emergency treatment has increased significantly ${ }^{[2]}$. Among the critically patients in the emergency room of each hospital, the proportion of elderly patients is the highest. As the elderly patients are older, more basic diseases, weak resistance, rapid changes in the

*Address for correspondence

E-mail:wyh875423@163.com 
condition, there is a potential risk ${ }^{[3]}$. Therefore, it is extremely important for the prognosis of patients to accurately evaluate the patient's condition and quickly take reasonable and effective measures, which is also a subject that clinical medical personnel need to face.

Modified Early Warning Score (MEWS) was proposed to detect "potentially critical illness" so that medical staff can intervene in time to improve clinical prognosis. The United Kingdom formulated a unified early warning score in 2012, named the National Early Warning Score (NEWS), as a standardized indicator to determine the severity of the disease and monitor changes in the disease; it has been widely promoted in China and UK. There are many elderly patients. This article mainly discusses the predictive value and feasibility of MEWS and NEWS on the outcome of elderly patients in China.

\section{CLINICAL DATA AND METHODS}

\section{General clinical data:}

A total of 1034 elderly patients from January 2019 to December 2019 in our hospital were selected as the research objects, including 563 males $(54.48 \%)$ and 471 females (45.52\%); the average age was $(75.23 \pm 12.56)$ y (range, 60-87 y). In addition, there were 355 cases $(34.33 \%)$ with cardiovascular and cerebrovascular diseases, 208 cases $(20.12 \%)$ with respiratory diseases, 293 cases $(28.39 \%)$ with digestive system diseases and 178 cases $(17.21 \%)$ with nervous system, endocrine system and other diseases.
Inclusion criteria-Patients admitted to the emergency department of the hospital; patients aged $60 \mathrm{y}$ or older; no mental illness. Exclusion criteria: patients with incomplete score data; patients with incomplete physiological parameters, examination results and treatment results required during treatment; elderly patients with non-traumatic death such as myocardial infarction; patients who died outside hospital. The patient's whereabouts and clinical data after $30 \mathrm{~d}$ are shown in Table 1.

\section{Methods:}

1034 elderly patients were collected the observation indicators after receiving the emergency department and the MEWS and NEWS scores were performed at the same time, as shown in Table 2. The MEWS scores index includes the patient's pulse rate, systolic blood pressure, respiratory rate, body temperature and consciousness. The NEWS scores adds age, respiratory support and oxygen saturation $\left(\mathrm{SpO}_{2}\right)$.

According to the actual outcome of patients, they were divided into intensive care unit (ICU) group (patients died during emergency stay and admitted to ICU) and general ward group (patients discharged from hospital, outpatient treatment and transferred to emergency or specialized general ward). The end point was $30 \mathrm{~d}$ and the prognosis included death or survival. Analyze the influencing factors and independent influencing factors of elderly critical illness and evaluate the effect of this score on the prognosis of elderly patients with

TABLE 1: GENERAL CLINICAL DATA AFTER 30 D

\begin{tabular}{|c|c|c|c|}
\hline & Contents & $\mathbf{n}$ & $\%$ \\
\hline \multirow[t]{2}{*}{ Emergency response } & CPR / Defibrillation & 61 & 5.90 \\
\hline & Invasive respiratory support (endotracheal intubation / tracheotomy) & 152 & 14.70 \\
\hline \multirow[t]{3}{*}{ Outcome } & Give up treatment or transfer to another hospital & 631 & 61.03 \\
\hline & Hospitalization (general ward) & 211 & 20.41 \\
\hline & Hospitalization (ICU) & 146 & 14.12 \\
\hline \multirow[t]{2}{*}{ Prognosis } & Death & 96 & 9.28 \\
\hline & Survival & 938 & 90.72 \\
\hline
\end{tabular}

TABLE 2: NEWS SCALE

\begin{tabular}{|c|c|c|c|c|}
\hline Variable & 0 & 1 & 2 & 3 \\
\hline Pulse rate (beats / min) & - & - & $111 \sim 130$ & $\leq 40$ or $\geq 131$ \\
\hline Systolic blood pressure (mmHg) & $111 \sim 219$ & $101 \sim 110$ & $91 \sim 100$ & $\leq 90$ or $\geq 220$ \\
\hline Respiratory rate (times / min) & $12 \sim 20$ & 9 11 & $21 \sim 24$ & $\leq 8$ or $\geq 25$ \\
\hline Temperature $\left({ }^{\circ} \mathrm{C}\right)$ & $36.1 \sim 38.0$ & $35.1 \sim 36.0$ or $38.1 \sim 39.0$ & $\geq 39.1$ & $\leq 35.0$ \\
\hline Consciousness & clear & Responding to sounds & Responding to pain & No response \\
\hline Age (years) & $<50$ & $50 \sim 59$ & $60 \sim 69$ & $\geq 70$ \\
\hline $\mathrm{SpO}_{2}(\%)$ & $\geq 96$ & $94 \sim 95$ & $92 \sim 93$ & $\leq 91$ \\
\hline Respiratory support & No oxygen intake & $\begin{array}{c}\text { Moderate and low flow } \\
\text { oxygen intake }\end{array}$ & $\begin{array}{l}\text { High flow oxygen } \\
\text { intake }\end{array}$ & $\begin{array}{l}\text { Ventilator } \\
\text { assistance }\end{array}$ \\
\hline
\end{tabular}


emergency by receiver operating characteristic curve (ROC curve).

\section{Quality Control:}

Before conducting investigations and studies, medical staff were trained and instructed. Patients and their families signed a consent form for treatment and care and a designated person was responsible for tracking the patient's outcome and recording prognostic observation indicators. The data was entered by two persons, reviewed and proofread.

\section{Statistical analysis:}

SPSS 20.0 was used to process the data. T test was used to compare the completion time of nursing measures between the two groups. The statistics of patients, family members and doctors to nurses was compared by chi square test. $\mathrm{p}<0.05$ was considered to be statistically significant.

\section{RESULTS AND DISCUSSION}

There were 211 elderly patients $(20.41 \%)$ in the general ward group and $146(14.12 \%)$ in the ICU group. There were no significant differences in gender, age, systolic blood pressure, body temperature and with or without trauma between the two groups of patients $(p>0.05)$. And the two groups had statistically significant differences in consciousness, respiratory support, mode of admission and renal failure $(\mathrm{p}<0.05)$. What's more, the pulse, respiratory rate, MEWS scores and NEWS scores of patients in the ICU group were higher than those in the general ward group and $\mathrm{SpO}_{2}$ was lower than those in the general ward group, the difference was statistically significant $(\mathrm{p}<0.05)$, as shown in Table 3 .

There were 938 elderly patients $(90.45 \%)$ in the survival group and $96(9.55 \%)$ in the death group. There were significant differences in consciousness, mode of admission and renal failure between the two groups ( $\mathrm{p}<0.05$ ). The pulse, respiratory rate, respiratory support, MEWS score and NEWS score of death group were higher than those of survival group, $\mathrm{SpO}_{2}$ was lower than that of survival group and the difference was statistically significant $(p<0.05)$. However, there were no significant differences in gender, age, systolic blood pressure, pain and body temperature between the two groups ( $\mathrm{p}>0.05)$, as shown in Table 4.

The comparison of MEWS score and NEWS score in judging the prognosis curve and prognosis resolution of emergency critical patients are shown in fig. 1 and
Table 5 respectively. The Area under curve (AUC), ROC of MEWS score was 0.886 , the $95 \%$ confidence interval was 0.872 to 0.900 , the cutoff point was $>4$, Youden index was 0.638 , the sensitivity was $76.00 \%$ and the specificity was $87.78 \%$.

The AUC ROC of the NEWS score was 0.916 , the $95 \%$ confidence interval was 0.902 to 0.928 , the cutoff point was $>6$, Youden index was 0.675 , the sensitivity was $90.00 \%$ and the specificity was $87.36 \%$. The index and sensitivity of the NEWS score was higher than that of MEWS score, but the specificity of the two scores had no significant difference ( $p<0.05)$, as shown in fig. 1 .

The median hospitalization time of 1034 patients was $308.25 \mathrm{~h}$ and the median cost of hospitalization was 48291.40 Yuan. There was a positive correlation between the two early warning scores and the total hospitalization expenses, but there was no linear correlation between the two early warning scores and the total hospitalization time, as shown in Table 5.

With the rapid development of medical technology and health service in China, it is necessary to improve the clinical treatment effect in emergency treatment. Objective, accurate and effective assessment of the condition and severity of emergency patients, especially for elderly patients with potential death risk, plays a key role in improving the prognosis and quality of life of patients ${ }^{[4-6]}$. In order to avoid misdiagnosis and even medical disputes caused by doctors' clinical experience in emergency treatment, some scholars have introduced a variety of disease risk assessment systems and methods. At present, there are many clinical disease risk assessment methods, including acute physiology and chronic health assessment II score ${ }^{[7]}$, rapid acute physiology score ${ }^{[8]}$, rapid emergency internal medicine score $^{[9]}$. However, the above methods have limitations such as more evaluation contents and longer evaluation time and are not practical for emergency patients ${ }^{[10]}$.

On the basis of the original, the NEWS added the score of $\mathrm{SpO}_{2}$ and oxygen absorption made slight adjustments in respiratory rate, body temperature, blood pressure and pulse rate. Our results showed that NEWS can effectively evaluate the condition changes of elderly patients with acute and severe emergency, especially in the aspect of emergency outcome. In this study, NEWS and MEWS were used to evaluate the outcome and prognosis of elderly critically ill patients in emergency department. The results showed that NEWS and MEWS in ICU group and death group were higher than those in general ward group and survival 


\begin{tabular}{|c|c|c|c|c|}
\hline Influence factors & General ward group $(n=146)$ & ICU group $(n=211)$ & $x^{2}$ & $\mathrm{p}$ \\
\hline Age & $75.32 \pm 10.95$ & $76.12 \pm 10.20$ & 2.551 & 0.105 \\
\hline \multicolumn{5}{|l|}{ Gender } \\
\hline Male & 53.41 & 55.21 & \multirow[t]{2}{*}{1.781} & \multirow[t]{2}{*}{0.237} \\
\hline Female & 46.59 & 44.79 & & \\
\hline Systolic pressure & $128.53 \pm 10.65$ & $129.47 \pm 12.09$ & 2.10 & 0.108 \\
\hline $\mathrm{SpO}_{2}$ & $96.88 \pm 3.21$ & $91.57 \pm 3.43$ & 7.23 & 0.001 \\
\hline Temperature & $36.64 \pm 0.27$ & $36.37 \pm 0.18$ & 1.03 & 0.64 \\
\hline Respiratory rate & $16.58 \pm 2.25$ & $21.27 \pm 4.15$ & 5.89 & 0.001 \\
\hline Pulse rate & $81.54 \pm 12.79$ & $87.43 \pm 14.89$ & 8.23 & 0.001 \\
\hline \multicolumn{5}{|l|}{ Consciousness } \\
\hline Clear & 178 & 2 & \multirow{4}{*}{10.25} & \multirow{4}{*}{0.001} \\
\hline Responding to sounds & 24 & 11 & & \\
\hline Responding to pain & 8 & 46 & & \\
\hline No response & 1 & 87 & & \\
\hline \multicolumn{5}{|l|}{ Trauma } \\
\hline Yes & 129 & 84 & \multirow[t]{2}{*}{1.05} & \multirow[t]{2}{*}{0.611} \\
\hline No & 82 & 62 & & \\
\hline \multicolumn{5}{|l|}{ Respiratory support } \\
\hline No oxygen intake & 18 & 83 & \multirow{4}{*}{10.55} & \multirow{4}{*}{0.001} \\
\hline Moderate and low flow oxygen intake & 16 & 35 & & \\
\hline High flow oxygen intake & 37 & 19 & & \\
\hline Ventilator assistance & 140 & 9 & & \\
\hline \multicolumn{5}{|l|}{ Mode of admission } \\
\hline Walk & 167 & 6 & \multirow{3}{*}{12.57} & \multirow{3}{*}{0.001} \\
\hline Need a hand/wheel & 36 & 21 & & \\
\hline Stretcher required/unable to move & 8 & 119 & & \\
\hline \multicolumn{5}{|l|}{ Dysuria } \\
\hline Yes & 36 & 126 & \multirow[t]{2}{*}{6.09} & \multirow[t]{2}{*}{0.001} \\
\hline No & 175 & 20 & & \\
\hline \multicolumn{5}{|l|}{ Pain } \\
\hline Yes & 108 & 70 & \multirow[t]{2}{*}{0.89} & \multirow[t]{2}{*}{0.722} \\
\hline No & 103 & 76 & & \\
\hline MEWS score & 2 & 4 & 7.21 & 0.001 \\
\hline NEWS score & 5 & 7 & 6.35 & 0.001 \\
\hline
\end{tabular}

group, which was consistent with the existing research results ${ }^{[11-13]}$. Therefore, as a new scoring model, NEWS has been recognized and adopted by clinical medical staff at home and abroad for its simple calculation and strong operability. In particular, it has achieved good application effect in the field of emergency and can well predict the condition and prognosis of emergency patients $^{[14]}$.

Various studies have pointed out that the total length of stay and the total cost of hospitalization are related to the complexity and severity of the patient's condition. If the patient's condition is complex and serious, the length and cost of hospitalization will increase accordingly. In this study, we found that the higher the total hospitalization expenses, the higher the scores of

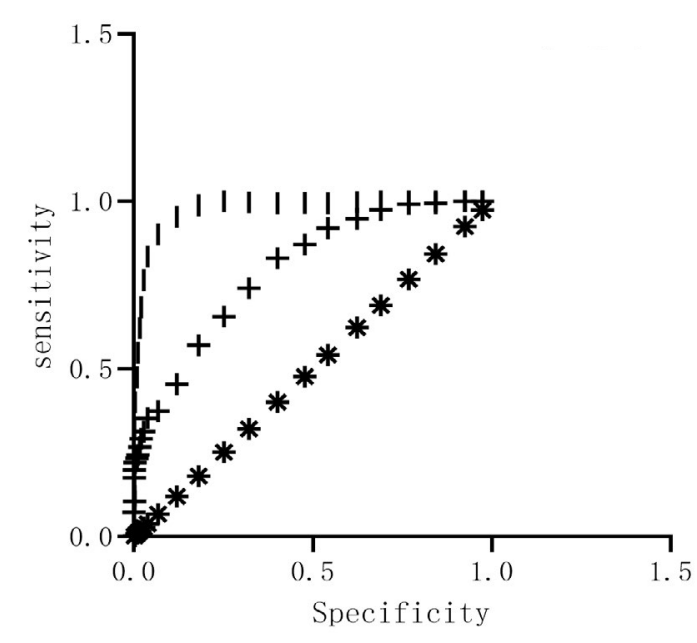

Fig. 1: MEWS score and NEWS score were used to evaluate prognosis. $(*)$ reference;

$(+)$ mews: (l) news

Special Issue 3, 2021 
www.ijpsonline.com

TABLE 4: COMPARISON OF INDEXES BETWEEN SURVIVAL GROUP AND DEATH GROUP

\begin{tabular}{|c|c|c|c|c|}
\hline Influence factor & Survival group $(n=938)$ & Death group $(n=96)$ & $x^{2}$ & $\mathrm{p}$ \\
\hline Age & $74.46 \pm 11.70$ & $76.45 \pm 8.37$ & 2.631 & 0.094 \\
\hline \multicolumn{5}{|l|}{ Gender } \\
\hline Male & 57.32 & 56.48 & \multirow[t]{2}{*}{1.884} & \multirow[t]{2}{*}{0.253} \\
\hline Female & 42.68 & 43.52 & & \\
\hline Systolic pressure & $127.20 \pm 9.31$ & $127.52 \pm 10.40$ & 0.932 & 0.753 \\
\hline Blood oxygen saturation & $97.25 \pm 3.17$ & $92.08 \pm 3.59$ & 5.39 & 0.001 \\
\hline Temperature & $36.21 \pm 0.13$ & $36.44 \pm 0.32$ & 1.16 & 0.69 \\
\hline Respiratory frequency & $16.26 \pm 2.01$ & $22.27 \pm 4.02$ & 4.94 & 0.001 \\
\hline Pulse & $80.33 \pm 11.15$ & $88.24 \pm 14.15$ & 7.69 & 0.001 \\
\hline \multicolumn{5}{|l|}{ Consciousness } \\
\hline Clear & 887 & 2 & \multirow{4}{*}{9.17} & \multirow{4}{*}{0.001} \\
\hline Responding to sounds & 41 & 2 & & \\
\hline Responding to pain & 9 & 9 & & \\
\hline No response & 1 & 87 & & \\
\hline \multicolumn{5}{|l|}{ Trauma } \\
\hline Yes & 641 & 61 & \multirow[t]{2}{*}{1.13} & \multirow[t]{2}{*}{0.611} \\
\hline No & 297 & 39 & & \\
\hline \multicolumn{5}{|l|}{ Respiratory support } \\
\hline No oxygen intake & 18 & 83 & \multirow{4}{*}{8.89} & \multirow{4}{*}{0.001} \\
\hline Moderate and low flow oxygen intake & 16 & 35 & & \\
\hline High flow oxygen intake & 37 & 19 & & \\
\hline Ventilator assistance & 140 & 9 & & \\
\hline \multicolumn{5}{|l|}{ Mode of admission } \\
\hline Walk & 867 & 6 & \multirow{3}{*}{11.43} & \multirow{3}{*}{0.001} \\
\hline Need a hand/wheel & 66 & 21 & & \\
\hline Stretcher required/unable to move & 5 & 119 & & \\
\hline \multicolumn{5}{|l|}{ Dysuria } \\
\hline Yes & 98 & 87 & \multirow[t]{2}{*}{6.29} & \multirow[t]{2}{*}{0.001} \\
\hline No & 840 & 9 & & \\
\hline \multicolumn{5}{|l|}{ Pain } \\
\hline Yes & 521 & 49 & \multirow[t]{2}{*}{1.00} & \multirow[t]{2}{*}{0.708} \\
\hline No & 417 & 47 & & \\
\hline MEWS score & 2 & 5 & 9.13 & 0.001 \\
\hline NEWS score & 3 & 7 & 7.39 & 0.001 \\
\hline
\end{tabular}

TABLE 5: RELATIONSHIP BETWEEN TWO EARLY WARNING SCORES AND TOTAL LENGTH OF STAY AND COST

\begin{tabular}{|c|c|c|c|c|}
\hline \multirow{2}{*}{ Score } & \multicolumn{2}{|c|}{ Total hospitalization expenses } & \multicolumn{2}{|c|}{ Total length of stay } \\
\hline & Correlation coefficient & $\mathbf{p}$ & Correlation coefficient & $\mathrm{p}$ \\
\hline MEWS score & 0.108 & 0.021 & 0.011 & 0.793 \\
\hline NEWS score & 0.156 & 0.001 & 0.026 & 0.652 \\
\hline
\end{tabular}

the two kinds of early warning scores. Therefore, the two early warning scores have a positive relationship with the total cost of hospitalization, which indirectly reflects that the two early warning scores have certain clinical guiding significance in predicting the hospitalization expenses of patients. Meanwhile, the study also found that there was no linear correlation between the total length of stay and the two early-warning scores, which may be related to the small number of samples. In addition, some patients (such as patients in general wards of internal medicine) have been stable, but still need to be treated in the hospital, which will affect the research results to a certain extent, that is, the score is not high, while the hospitalization time is longer.

In conclusion, the NEWS score is closer to the actual situation of elderly patients and can reflect the severity and changes of elderly patients more accurately and comprehensively than MEWS score. In addition, NEWS has a stronger ability to predict the prognosis of 
patients, which can effectively help emergency medical workers to take timely intervention measures and ultimately achieve the purpose of reducing the mortality of elderly patients and improving their quality of life.

\section{Conflicts of interest:}

The authors report no conflicts of interest.

\section{Acknowledgements:}

This work was supported by the Xuanwu Hospital, Capital Medical University.

\section{REFERENCES}

1. Jones M. NEWSDIG: The national early warning score development and implementation group. Clin Med 2012;12:501-3.

2. Party IS. National clinical guideline for stroke. London: Royal College of Physicians 2012.

3. Fullerton JN, Price CL, Silvey NE, Brace SJ, Perkins GD. Is the Modified Early Warning Score (MEWS) superior to clinician judgement in detecting critical illness in the prehospital environment?. Resuscitation 2012;83:557-62.

4. Subbe CP, Kruger M, Rutherford P, Gemmel L. Validation of a modified Early Warning Score in medical admissions. QJM 2001;94:521-6.

5. Smith GB, Prytherch DR, Meredith P, Schmidt PE, Featherstone PI. The ability of the National Early Warning Score (NEWS) to discriminate patients at risk of early cardiac arrest, unanticipated intensive care unit admission and death. Resuscitation 2013;84:465-70.

6. Prytherch DR, Smith GB, Schmidt PE, Featherstone PI. ViEWS-towards a national early warning score for detecting adult inpatient deterioration. Resuscitation 2010;81:932-7.

7. Saillant NN, Earl-Royal E, Pascual JL, Allen SR, Kim PK,
Delgado MK, et al. The relationship between processes and outcomes for injured older adults: a study of a statewide trauma system. Eur J Trauma Emerg Surg 2017;43:121-7.

8. Day T, Oxton J. The national early warning score in practice: a reflection. Br J Nurs 2014;23:1036-40.

9. Khan N, Carle C. Should the national early warning score be adopted throughout the NHS?. Br J Hosp Med 2014;75:478.

10. Kellett J, Murray A. How to follow the NEWS. Acute Med 2014;13:104-7.

11. Siracuse JJ, Odell DD, Gondek SP, Odom SR, Kasper EM, Hauser CJ, et al. Health care and socioeconomic impact of falls in the elderly. Am J Surg 2012;203:335-8.

12. Badriyah T, Briggs JS, Meredith P, Jarvis SW, Schmitdt PE, Featherstone PI, et al. Decision-tree early warning score (DTEWS) validates the design of the National Early Warning Score (NEWS). Resuscitation 2014;85:418-23.

13. Mangram AJ, Mitchell CD, Shifflette VK, Lorenzo M, Truitt MS, Goel A, et al. Geriatric trauma service: a one-year experience. J Trauma Acute Care Surg 2012;72:119-22.

14. Tirkkonen J, Olkkola KT, Huhtala H, Tenhunen J, Hoppu S. Medical emergency team activation: performance of conventional dichotomised criteria versus national early warning score. Acta Anaesthesiol Scand 2014;58:411-9.2.

15. Tirkkonen J, Olkkola KT, Huhtala H, Tenhunen J, Hoppu S. Medical emergency team activation: performance of conventional dichotomised criteria versus national early warning score. Acta Anaesthesiol Scand 2014;58:411-9.

This is an open access article distributed under the terms of the Creative Commons Attribution-NonCommercial-ShareAlike 3.0 License, which allows others to remix, tweak, and build upon the work non-commercially, as long as the author is credited and the new creations are licensed under the identical terms

This article was originally published in a special issue, "Evolutionary Strategies in Biomedical Research and Pharmaceutical Sciences" Indian J Pharm Sci 2020:83(3) Spl issue;14-19 